\title{
ORQUIEPIDIDIMITIS POR BRUCELA
}

\author{
J.M. ALAPONT ALACREU, L. GÓMEZ LÓPEZ, F. DELGADO, J.L. PALMERO MARTÍ, J.J. \\ PACHECO BRU, J.L PONTONES MORENO, J.F. JIMÉNEZ CRUZ
}

Servicio de Urología. Hospital Universitario La Fe. Valencia.

Actas Urol Esp. 28 (10): 774-776, 2004

\section{RESUMEN}

ORQUIEPIDIDIMITIS POR BRUCELA

La brucelosis es una zoonosis que puede afectar al hombre. La orquitis brucellosa es una complicación rara de esta enfermedad sistémica (2-14\%). Puede evolucionar a una forma necrotizante que hay que distinguir de otras orquiepididimitis granulomatosas (TBC y Salmonela). El tratamiento con antimicrobianos específicos puede evitar la orquiectomía y además previene la afectación contralateral y las manifestaciones sistémicas.

Presentamos un caso de orquiepididimitis brucelosa en un joven de 19 años que vivía en una gran ciudad y en el que la anamnesis fue crucial para el diagnóstico. Además realizamos una revisión del diagnóstico y manejo de esta rara infección testicular.

PALABRAS CLAVE: Orquiepididimitis. Brucelosis.

\section{ABSTRACT}

\section{BRUCELLAR ORCHIEPIDIDYMITIS}

Brucellosis is a cause of human disease, especially in regions whose brucellosis in animals is enzootic. Brucella orchitis is a rare complication of systemic brucellosis (2-14\%). Necrotizing orchitis is posible and it must be distinguished from necrotizing involvement arising from other pathogens (TB or Salmonella). Treatment with specific antimicrobial medication helps to avoid unnecessary orchiectomy and prevent infectious disease in the contralateral testis as well as systemic manifestations.

We report a case of brucellar epididymo-orchitis presenting as an acute scrotal mass in a 19 years old male who lived in a city. The anamnesis was crucial in the diagnosis of this rare testicular infection. We review the diagnosis and management of this patology.

KEY WORDS: Orchiepidydimitis. Brucellosis.

$\mathrm{L}^{\mathrm{a}}$ a brucelosis es una enfermedad infecciosa producida por las bacterias del género Brucella. Tiene una distribución mundial, siendo España el país europeo con mayor incidencia de ésta, con cifras de hasta 20 casos por 100.000 habitantes ${ }^{1}$, aunque dado que no existe un programa coordinado nacional de lucha contra la enfermedad, la incidencia es muy distinta de unas regiones a otras: el mayor número está en la meseta y el sur de la península, y el menor en Cantabria y Asturias. La Comunidad Canaria históricamente aparece libre de brucelosis ${ }^{2}$.
En la mayoría de las ocasiones la enfermedad humana en España es debida a B. melitensis, que tiene mayor contagiosidad y patogenicidad. La localización orquiepididimaria es del $2-14 \%^{3-5}$. La incidencia es mayor en áreas rurales, donde existe mayor contacto con animales domésticos (cabras, ovejas, vacas, cerdos) y es una enfermedad de carácter casi exclusivamente profesional. Los casos de orquiepididimitis brucelosa en zonas urbanas son excepcionales por lo que no se suele tener en cuenta en el diagnóstico diferencial de 
escroto agudo. Presentamos un caso de orquiepididimitis brucelosa en un joven de 19 años que vivía en un área metropolitana.

\section{CASO CLÍNICO}

Paciente varón de 19 años, estudiante, sin antecedentes médico-quirúrgicos de interés, que consulta por persistencia de fiebre y dolor en testículo izquierdo. Refiere que el cuadro había comenzado hacía 10 días, cuando fue diagnosticado por su médico de atención primaria de una orquiepididimitis, recibiendo tratamiento con amoxicilina-clavulánico y diclofenaco, sin notar ninguna mejoría y persistiendo picos febriles.

Cuando lo valoramos el paciente presenta un teste izquierdo aumentado de tamaño, tumefacto y doloroso a la palpación. En la anamnesis no refiere contacto con ningún tipo de ganado. Entre las exploraciones complementarias solicitadas en puertas de urgencia destacan: analítica de sangre: 11.500 leucocitos $/ \mathrm{mm}^{3}, \quad 72 \%$ neutrófilos; analítica de orina: sin hallazgos patológicos; ecografía escrotal (Fig. 1): teste derecho normal, teste izquierdo y cabeza de epidídimo aumentados de tamaño, homogéneos, sin colecciones líquidas intraparenquimatosas y con hidrocele reaccional no tabicado.

Instauramos tratamiento empírico parenteral con ciprofloxacino y tobramicina, siendo la evolución posterior tórpida y persistiendo los picos febriles vespertinos. El resultado de los urinocultivos y hemocultivos solicitados al ingreso del paciente fueron negativos.

Ante la mala evolución del paciente y el cuadro clínico que presentaba insistimos en la anamnesis y el paciente recordó que hacía 4 meses había estado en una granja-escuela trabajando durante 1 semana ayudando a un pastor a cuidar sus ovejas. Solicitamos el test de rosa de Bengala en sangre que sugirió la etiología brucelosa. La serología y el test de Coombs (1/2560) fueron positivos y el hemocultivo confirmó la presencia de $B$. mellitensis. Instauramos tratamiento con doxiciclina y rifampicina (sensible en antibiograma) durante 45 días y el paciente evolucionó de manera satisfactoria, con desaparición de la sintomatología y deshinchazón del testículo, quedando una leve induración a nivel epididimario a los 6 meses de seguimiento.

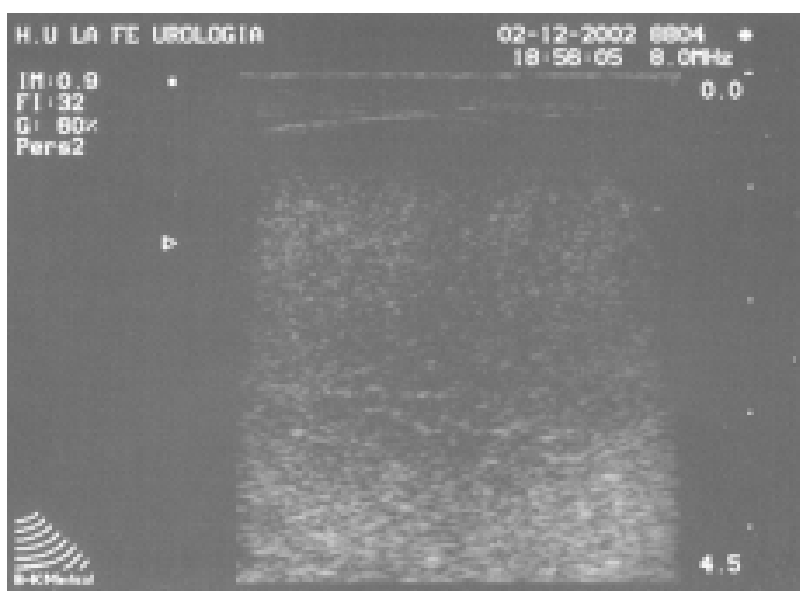

FIGURA 1 Ecografia escrotal.

\section{DISCUSIÓN}

Brucelosis es el término utilizado para definir la enfermedad producida por bacterias del género Brucella. Estos patógenos son cocobacilos gramnegativos, inmóviles, no esporulados, aerobios, oxidasa y catalasa positivos. Son intracelulares (sobreviven en las células fagocíticas). Crecen lentamente en medios de cultivo habituales y se perpetúan a través de la infección de sus huéspedes naturales, los animales. Se transmite por vía digestiva (ingestión de productos lácteos no controlados) o vía respiratoria, cutánea y conjuntival (contacto con animales enfermos). No se ha demostrado la transmisión entre personas ${ }^{6}$. La bacteria pasa desde los linfáticos hasta la sangre venosa, donde es transportada por los neutrófilos y los monocitos hasta el hígado, bazo, médula ósea y ganglios linfáticos principalmente, aunque puede llegar a cualquier órgano.

La brucelosis puede ser asintomática, cursando únicamente con pruebas serológicas de infección. Cuando produce síntomas éstos pueden dividirse en brucelosis aguda, formas localizadas y brucelosis crónica. La orquiepididimitis por brucela es una forma localizada relativamente infrecuente, apareciendo entre un 2-14\% de brucelosis sistémicas $^{3-5}$ (segunda forma localizada más frecuente tras las complicaciones osteoarticulares).

La afectación testicular suele ser unilateral y clínicamente es igual a cualquier orquiepididimitis granulomatosa. Las formas bilaterales no se suelen asociar a atrofia o esterilidad ${ }^{1}$. En algunos 
casos se ha descrito una forma necrotizante con formación de abscesos intratesticulares ${ }^{7,8}$. Debemos sospecharla siempre que exista el antecedente de contacto con animales (cabras, ovejas, vacas), ingestión de leche (o derivados de ésta) no pasteurizada, episodio sistémico previo de brucelosis y en los casos que no evolucionan de forma satisfactoria con el tratamiento antibiótico empírico.

Los hallazgos clínicos y de laboratorio fueron descritos por Young ${ }^{9}$ en 1983. El hemocultivo positivo para esta bacteria confirma el diagnóstico. Las pruebas serológicas (más rápidas que el hemocultivo) tienen una alta especificidad por lo que el test de rosa de Bengala nos permite una aproximación diagnóstica inmediata. El test de Coombs antibrucela es la prueba serológica que mejores resultados ofrece y su negatividad excluye el diagnóstico.

El tratamiento con tetraciclina y estreptomicina suele ser eficaz, pero la pauta recomendada es la asociación de rifampicina (600 $\mathrm{mg} /$ día) con doxiciclina (200 mg/día) durante un periodo mínimo de 6 semanas (Joint FAO/WHO Report, 1986). Este tratamiento debe ser precoz y completo para evitar las formas abscesificantes y necrosantes, en las que está indicada la orquiectomía $^{8}$. En caso de recaída se debe administrar nueva tanda antibiótica y durante más tiempo.

Ante una orquiepididimitis de evolución tórpida debemos tener presente la posibilidad de la etiología brucelosa, especialmente en áreas endémicas y en personas que hayan podido tener contactos con ganado enfermo o ingesta de derivados lácteos no controlados. Es muy importante hacer hincapié en que el contacto de riesgo podría haber ocurrido varios meses antes de la orquiepididimitis (como el caso que presentamos) por lo que en la anamnesis hay que tener en cuenta este factor.

\section{REFERENCIAS}

1. Ariza J. Brucelosis. En Farreras P, Rozman C (Ed). Medicina interna. Doyma. Barcelona 1992;2253-2258.

2. Ariza J: Brucelosis: Algunos aspectos de su epidemiología . Enf Infecc Microbiol Clin 1989;7:517-518.

3. Ibrahim AIA, Awad R, Shetty Sd, Saad M, Bilal Ne.: Genitourinary complications of Brucellosis. Br J Urol 1988;61: 294-298.

4. Patel PJ, Kolawole TM, Sharma N, Al-Faqih S: Sonographic findings in scrotal Brucellosis. J Clin Ultrasound 1988;16: 483-486.

5. Afsar H, Baydar I, Sirmatel F. Epididimo-orchitis due to Brucellosis. Br J Urol 1993;72:104-105.

6. Peña P, Gutiérrez A. Brucelosis. Enf Infecc Microbiol Clin 1993;11:403-409.

7. Fernández A, Jiménez M, Cruces F, Guil M, Bethencurt R, Dehaini A, et al Orquitis brucelosa abscesificada. Actas Urol Esp 1990;14:387-389.

8. Castillo JL, Bravo de Rueda C. Brucelosis genital. Causa rara de absceso testicular. Arch Esp Urol 1994;47:533-536.

9. Young EJ: Human Brucellosis. Rev Infect Dis 1983;5:821842.

Dr. J.M. Alapont Alacreu

Servicio de Urología

Hospital Universitario La Fe

Avda. Campanar no 21

46009 Valencia

e-mail: jmalapont@mundofree.com

(Trabajo recibido el 16 diciembre de 2004) 